\title{
김부겸의원 발의 대외원조기본법안 관련 진술서
}

김 은 미 / 이화여자대학교 국제대학원 교수

\section{1. 전체법안}

- $\mathrm{OECD} \mathrm{DAC} \mathrm{가입을} \mathrm{앞두고} \mathrm{매우} \mathrm{시의} \mathrm{적절한}$ 법안 상정이다.

- 하지만 명목상의 법률이 아닌 보다 체계적이 고 전략적인 국제개발원조 수행을 위한 구체 적인 방안으로서의 방향성을 가지고 본 법안 에 대해 검토해야 한다.

- 선진공여국은 ODA 정책집행에 있어 통합관 리체계를 갖추고 일원화되어 전략적인 원조를 수행하고 있으며, 선진외교의 한 부분으로 국 제개발원조를 인식하고 있다.

- 미국, 캐나다, 호주, 뉴질랜드는 '외교부의 전 략수립 $\rightarrow$ 하위기관의 집행 및 평가 의 전형 적인 체계를 가지고 있다.
- 영국과 네덜란드는 국제개발의 오랜 역사를 바탕으로 개발협력을 전담하는 부처를 설립 하여 부처 내 '전략 $\rightarrow$ 집행 $\rightarrow$ 평가 $\rightarrow$ 전략' 에 이르는 환류체계를 효율적으로 구축하고 있다.

- 외무성 산하 유상원조와 무상원조로 이원화 된 집행체계를 가진 일본은 2008년까지 외무 성과 JICA중심의 통합계획을 발표했다.

- 따라서 한국의 국제개발협력 관련 법안 역시 이러한 국제적 추세와 외교정책을 반영하여 검토 · 수립되어야 한다.

\section{2. 법안명과 제 1 조 (목적)}

- 대외원조' 는 원조 공여 시 수원국의 이익을 반 영하여 원조의 효과성과 효율성을 높이고자 하는 공여국 중심의 용어이고 이는 국제적 노 
력에 부합하지 않기 때문에 '국제개발협력' 또 는 '개발협력' 으로 용어의 수정이 필요하다.

\section{3. 제2조 (기본이념)}

대외원조는 개발도상국의 빈곤퇴치를 위한 지속가 능한 개발을 지원하고 인도주의와 호혜협력을 바 탕으로 인류평화와 공동번영의 추구를 기본이념으 로 한다.

- 인도주의와 호혜주의는 ODA 공여 초기의 이 념으로 국제개발협력의 이상을 담고 있으나, 국제사회의 부름에 응하는 수동적인 개념을 내포할 수 있다는 비판적인 시각도 존재한다.

- 실제 한국의 ODA는 2000년대 이후 외교정책 의 일부로서 공여국인 한국과 수원국의 이익 을 모두 반영하고자 하는 양상을 보이고 있으 며, 따라서 기본이념 역시 "인도주의와 호혜협 력을 바탕으로 하고 국제사회의 법률과 우리 나라의 정책을 고려하여” 인류평화와 공동번 영을 추구하는 것으로 개정되어야 할 것이다.

\section{4. 제3조 (정의)}

- 무상원조 및 유상원조와 더불어 $\mathrm{OECD} \mathrm{DAC}$ 기준에 맞는 '긴급구호자금 (emergency aid)' 와' 기술협력 (technical assistance)' 대한 논 의도 구분해서 논의되어야 한다.

\section{5. 제6조 (대외원조의 책임기관 등)}

- 원조유형별로 특히 무상원조와 유상원조 기관 을 나누어 지정하는 것은, 보다 통합적이고 전 략적인 원조활동을 강조하고 있는 국제적 논 의에 부합하지 않는다. 실제로 선진공여국일 수록 정부부처급 기관으로 일원화된 $\mathrm{ODA}$ 운 영체계를 보인다. (영국의 DFID, 네델란드의 외부무 내 개발장관 체제 등)

- 일본의 경우 현재 분리되어 있는 유 - 무상 원 조체계를 2006. 8. 10 이후부터 JICA 중심으 로 유-무상 원조를 통합하는 개선안을 마련 하여 추진 중이다.

- 동 법안은 정책의 일관성과 프로그램 중복, 조 정의 문제를 안고 있는 현행 이원화된 체계를 법률로 고착화한다는 우려가 있고 이는 국제 적 논의를 역행한다는 위험이 있다.

\section{6. 제7조 (대외원조정책위원회)}

- 국무총리 소속의 대외원조정책위원회의 명칭 은 법안명과 같이 '국제개발협력위원회' 또는 '개발협력위원회' 로 용어를 수정해야 한다.

- 15 인의 위원 구성을 20-25명으로 확대하여 정부 외부 전문가들이 $50 \%$ 를 구성하게 함으 로써 국가의 이익에 부합하고 수원국의 필요 
를 충족시킬 수 있는 균형적인 ODA 원조체계 를 유지할 수 있어야 한다.

- '위원회' 의 역할을 좀더 명확하게 규정할 필요 가 있음. 2006년 1월 26일 국무총리를 위원장 으로 하는 국제개발협력정책위원회가 발족되 고 16 개 부처장관, 2 개 정부기관장과 민간대표 가 참여하는 정책의결기구로 설립되었으나, 1 차 회의 이후 활동 기록이 전무한 상황이다.
- 부처 간 조정이 힘들었던 원인은 부처 간 실무 협의 채널의 부재 때문이 아니라 유- 무상 원 조가 이원화되어 집행되고 있기 때문이다.

- 따라서 “조정”과 “전략수립”의 역할을 분명히 하지 않은 ‘위원회’ 는 이원화된 체계를 오히 려 강화하고, 그 스스로는 유명무실화되는 길 을 걸을 수밖에 없다. 또한 위원회 활동의 정 례화, 권한 및 위상의 구체적 확립 등이 선행 되어야 한다.

- 다음의 과정을 목표로 상정해 볼 수 있다.

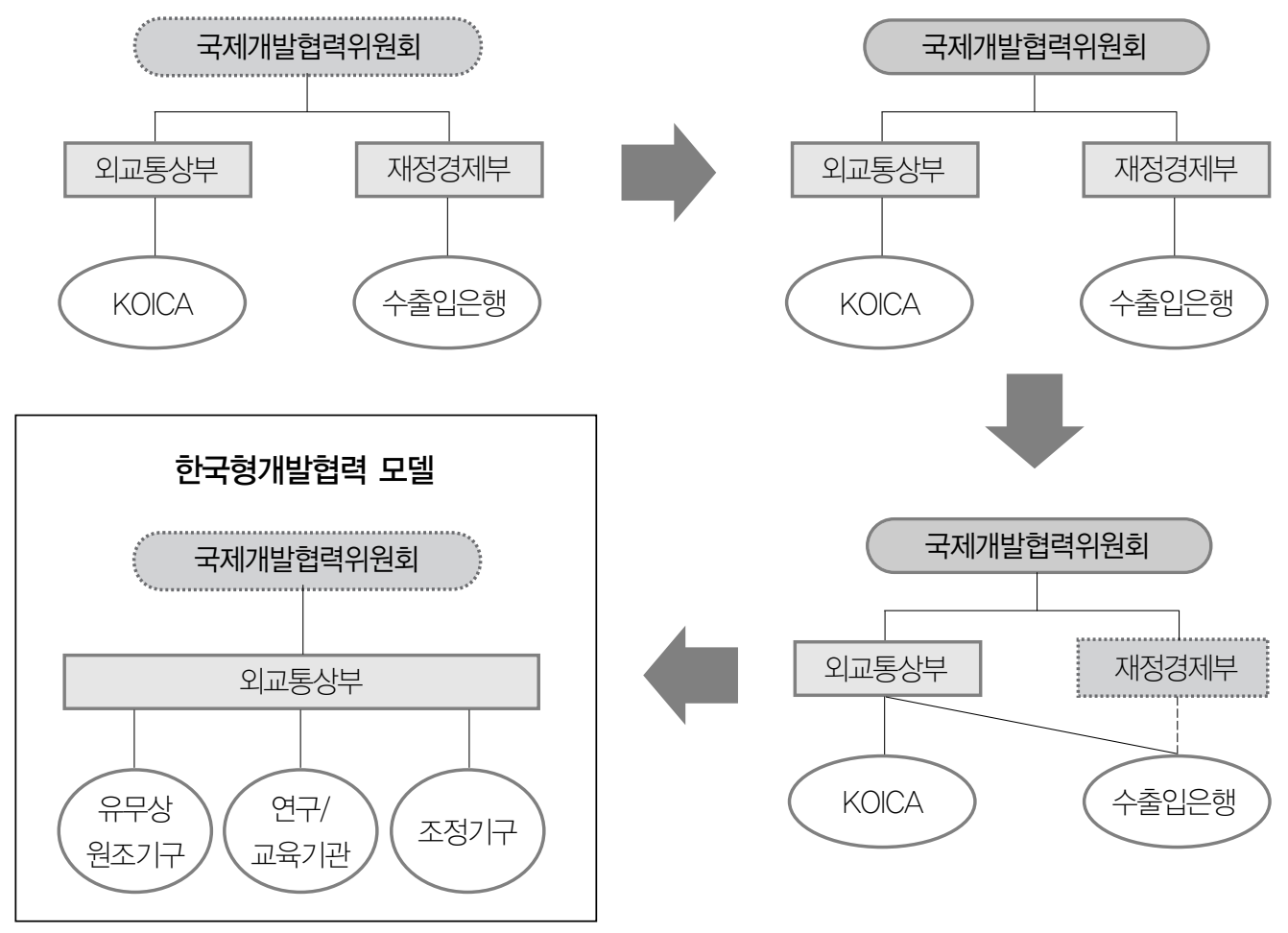




\section{7. 제10조 (대외원조에 대한 평가)}

- 체계적인 모니터링 및 평가 시스템을 갖추는 것은 선진 $\mathrm{ODA}$ 집행체계에 있어서 중요한 이 슈로 부각되고 있다.

- 독립적인 평가기관 또는 평가 부서를 설치하 여 평가 및 모니터링의 객관성을 높이고 이 후 유사 프로젝트 입안에 그 결과를 반영하 고 노하우를 축적하는 순환구조가 확립되어 야 한다.
- 이러한 필요성에도 불구하고 현 법안에는 평 가 체계에 대한 내용은 거의 없어 정책집행에 있어 환류를 통한 개선’ 이 불가능하다.

- 우선 평가지표 개발을 위한 위원회를 '국제개 발협력위원회' 아래에 설립하고, 이 위원회를 독립적인 평가기관으로 발전시키는 방안도 검 토 가능하다. 평가위원은 정책평가 전문가와 $\mathrm{ODA}$ 전문가, 프로젝트 전문가를 위촉하여 운 영하며, 이를 자료화하여 공유함으로써 환류 체계를 완성토록 할 수 있다. 